\title{
Dados para uma Estratégia de Intervenção na Formação Contínua de Professores de Física e Química
}

A.F. Cachapuz ${ }^{\text {a }}$

I. M. Malaquias ${ }^{\text {a }}$

I. P. Martins ${ }^{a}$

Marília F. Thomaz

N. Vasconcelos ${ }^{a}$
Apresentam-se os resultados obtidos num estudo empírico, envolvendo 704 professores de Física e Química a leccionar em escolas secundárias e $C+S$ de todos os distritos do continente em 1987.*

$O$ estudo teve como objectivos fundamentais investigar: (i)em quais dos aspectos relacionados com o ensino de $F / Q$ (por exemplo científicos, metodológicos, etc.) os professores sentem maiores dificuldades; (ii) há quanto tempo os professores não frequentam cursos ou acções de formaçāo em diferentes áreas; (iii) quais as razões, identificadas pelos professores, para a não frequência desses cursos/acções; (iv) que tipo de actividades de formação são identificadas pelos professores como sendo as que melhor os poderão ajudar a superar as dificuldades por eles apontadas.

A análise dos resultados foi feita em função das variáveis: experiência profissional, formação académica, situação profissional e predominância do nível de ensino leccionado pelos professores.

Os resultados desta investigaçâo sugerem implicaçōes educacionais a nível dos programas de formação contínua de professores de Física e Química, em particular a necessidade de pôr maior ênfase em acçōes nas áreas de avaliação da aprendizagem dos alunos e organização e funcionamento da escola, um aumento do número de acçōes antecedidas duma divulgação verdadeiramente eficaz junto dos professores, uma revisão dos conteúdos e orientações dessas activiaades de modo que elas ajudem realmente os professores a ultrapassarem as dificuldades por eles apontadas e também a necessidade da sua creditação de modo a incentivar externamente a participação dos professores.

Os resultados sugerem também que a licenciatura em Física e Química tem proporcionado uma formaçâo mais equilibrada do que qualquer outro tipo de licenciatura, permitindo aos professores uma mais fácil adaptaçāo às necessidades da sua prática docente, identificando assim este grupo como o menos carenciado de acçōes de F.C.

\footnotetext{
* Estes estudo insere-se no projecto de investigação "O Ensino e a Aprendizagem da Física e da Química: análise da situação actual no ensino secundário e propostas para o futuro face aos novos desafios científico-tecnológicos», subsidiado pelo Instituto Nacional de Investigação Científica, Contrato $\mathrm{n}^{\circ} 85$ / $/ \mathrm{CEX} / 3$. Sobre o tema deste artigo foi apresentada uma comunicação ao Colóquio Internacional «Perspectivas da Educação para o Ano 2000», realizado na Universidade de Trás-os-Montes, Vila Real, nos dias 29, 30 e 31 de Maio de 1989.
}

\section{INTRODUÇÃO}

A rápida evolução do conhecimento em várias áreas do saber, o desenvolvimento fascinante da tecnologia e a própria evolução da sociedade nos seus valores e nas suas relações inter-pessoais, são aspectos actuais que hoje em dia colocam importantes desafios a nível da formação de professores. A formação contínua (F.C.) pode ser uma estratégia possível de intervenção tendo como objectivo ajudar os professores a ultrapassarem as dificuldades na adaptação permanente às exigências decorrentes deste progresso científico e tecnológico, das transformações sociais e da vida cultural. A Lei de Bases do Sistema Educativo (lei no 46/86, de 14 de Outubro), definindo a F. C. como um direito de todos os docentes, reconhece a sua imprescindibilidade neste processo de adaptação. Também as recomendações da Comunidade Europeia, bem como outras entidades internacionais, se orienta neste sentido definindo o perfil dos professores, como agentes capazes de, numa sociedade em constante mutação, responder à nova população escolar e aos novos conteúdos de ensino, utilizar fontes alternativas de conhecimento e novos métodos e técnicas pedagógicas.

Como é reconhecido por responsáveis do sistema educativo no nosso País, «a este conjunto dinâmico de exigências profissionais tem de corresponder uma estrutura de formação contínua que, simultaneamente satisfaça as solicitações dos professores, as necessidades dos alunos e as prioridades definidas pelo sistema educativo no contexto da reforma da educação e no quadro da política de regionalização e da autonomia da escola» [1].

As bases para uma eficaz estrutura de programas de F. C. têm que ser encontradas através de trabalhos de investigação educacional tal como faz notar Hofstein [2], «estamos hoje numa era em que cada vez mais nos temos que apoiar em dados e resultados de investigação».

Pretendeu-se neste estudo fazer um levantamento prévio, ainda que sumário, das solicitações dos professores e do tipo de actividades que eles consideram mais importantes para a sua adaptação às novas exigências educacionais. Embora se trate de um estudo de percepções sujeito portanto a limitações, é nossa convicção que ele pode contribuir para delinear adequadas estratégias de intervenção a nível de F. C.. Os objectivos principais do estudo são investigar: 
(i) em quais dos aspectos relacionados com o ensino de F/Q, nomeadamente aspectos científicos de Física, aspectos científicos de Química, aspectos socio-psicológicos, aspectos metodológicos do ensino de Física e do ensino de Química, aspectos de avaliação da aprendizagem dos alunos e da organização e funcionamento da escola os professores sentem mais dificuldades;

(ii) há quanto tempo os professores não frequentam cursos ou acções de formação nas diferentes áreas correspondentes aos aspectos atrás considerados;

(iii) quais as razões, apontadas pelos professores, para a não participação nessas acções;

(iv) que tipo de actividades de formação são identificadas pelos professores como sendo as que melhor os poderão ajudar a superar as dificuldades por eles encontradas.

\section{MÉTODO}

\section{População}

Neste estudo empírico, cuja recolha de dados se iniciou em 1987, estiveram envolvidos 704 professores de Física e Química (cerca de $30 \%$ dos professores em exercício de, funções) a leccionar em escolas secundárias e $\mathrm{C}+\mathrm{S}$ de todos os distritos do continente. Através de um modelo bietápico e sequencial foi seleccionada uma amostra estruturada tendo em conta a representatividade dos distritos e tipos de escolas envolvidas. A amostra ficou assim constituída por 521 professores.

Os quadros I, II, III e IV apresentam a caracterização da amostra em termos de experiência profissional, formação académica, situação profissional e predominância do nível de ensino leccionado pelos professores.

QUADRO I

Caracterização da amostra em termos de EXPERIÊNCIA PROFISSIONAL

\begin{tabular}{|c|c|c|c|c|c|c|}
\hline $\begin{array}{l}\text { Experiência } \\
\text { profissional } \\
\text { (anos) }\end{array}$ & $\begin{array}{c}\text { Início de } \\
\text { actividades } \\
\text { (0) }\end{array}$ & $1-5$ & $6-10$ & $11-15$ & $16-20$ & $>20$ \\
\hline $\begin{array}{l}\text { Número } \\
\text { de } \\
\text { Porfessores }\end{array}$ & 55 & 117 & 87 & 102 & 60 & 90 \\
\hline
\end{tabular}

QUADRO II

Caracterização da amostra em termos de FORMAÇÃO ACADÉMICA

\begin{tabular}{|c|c|c|c|c|}
\hline & Física & Química & Física e Química & Outra \\
\hline Licenciatura & 29 & 112 & 139 & 82 \\
\hline Bacharelato & 10 & 60 & 6 & 34 \\
\hline
\end{tabular}

(A percentagem de não respostas engloba os professores que não responderam e os que não completaram qualquer licenciatura ou bacherelato).

QUADRO III

Caracterização da amostra em termos de SITUAÇÃO PROFISSIONAL

\begin{tabular}{|c|c|c|c|c|}
\hline $\begin{array}{c}\text { Situação } \\
\text { profissional }\end{array}$ & $\begin{array}{l}\text { Estagiá- } \\
\text { ria/o }\end{array}$ & $\begin{array}{l}\text { Profissionali- } \\
\text { zanda/o }\end{array}$ & $\begin{array}{c}\text { Provi- } \\
\text { sório }\end{array}$ & $\begin{array}{c}\text { Profissionali- } \\
\text { zada/o }\end{array}$ \\
\hline N. ${ }^{9}$ de Professores & 25 & 23 & 114 & 351 \\
\hline
\end{tabular}

QUADRO IV

Caracterização da amostra em termos de PREDOMINÂNCIA DO NÍVEL DE ENSINO LECCIONADO PELOS PROFESSORES

\begin{tabular}{|c|c|c|}
\hline $\begin{array}{l}\text { Nível de ensino } \\
\text { (predominância }\end{array}$ & Básico ( $3^{\circ}$ ciclo) & Secundário \\
\hline $\mathrm{N}^{\circ}$ de Professores & 243 & 229 \\
\hline
\end{tabular}

(A percentagem de não respostas engloba os professores que não responderam ou não tinham predominância em qualquer dos níveis de ensino).

\section{Questionário}

Os dados para este estudo foram obtidos através das respostas dadas a uma parte dum questionário [3], individual, validado previamente por nove juízes independentes e destinado a um estudo mais alargado sobre o ensino de Física e Química em Portugal.

\section{RESULTADOS}

Os resultados que se apresentam (em percentagem) dizem respeito às respostas dadas aos itens do questionário referente às quatro questões pertinentes para o estudo, nomeadamente i) em quais dos aspectos relacionados com o ensino da F/Q (científicos de Física, científicos de Química, socio-psicológicos, etc.) os professores sentem mais dificuldades; ii) há quanto tempo os professores não frequentam cursos ou acções de formação nas diferentes áreas atrás consideradas; iii) quais as razões para a não frequência desses cursos/ acções; e iv) que tipo de actividades de formação consideram mais importantes.

\section{Dificuldades encontradas pelos professores no exercício das suas funçōes docentes}

Com o objectivo de investigar em quais dos aspectos relacionados com o ensino de F/Q os professores sentiam maiores dificuldades inclui-se no questionário a seguinte questão:

«Indique para cada um dos aspectos as dificuldades que sente no exercício das suas funções docentes

- aspectos científicos de Física

- aspectos científicos de Química

- aspectos socio-psicológicos

- aspectos metodológicos do ensino da Física

- aspectos metodológicos do ensino da Química

- avaliação da aprendizagem dos alunos

- organização e funcionamento da escola»

A questão em análise foi feita em termos dos professores que, frequentemente + quase sempre, $(c+d)$, sentiam dificuldades em função das quatro variáveis independentes.

\section{Dificuldades encontradas e experiência profissional}

Para a análise desta questão a experiência profissional dos professores foi operacionalizada em termos do número de anos de ensino até Outubro de 1986 (ver ref. 3).

Os dados são apresentados na tabela I 
TABELA I

Dificuldades encontradas nos diferentes aspectos (\%)

\begin{tabular}{|l|c|c|c|c|c|}
\hline \multicolumn{1}{|c|}{ Dificuldades } & $\begin{array}{c}\text { (0) } \\
\text { nunca } \\
\text { sente }\end{array}$ & $\begin{array}{c}\text { (a) } \\
\text { raramente }\end{array}$ & $\begin{array}{c}\text { (b) } \\
\text { de vez em } \\
\text { quando }\end{array}$ & $\begin{array}{c}\text { (c+d) } \\
\text { frequentemente } \\
\text { +qusa sempre }\end{array}$ & $\begin{array}{c}\text { não } \\
\text { respostas }\end{array}$ \\
\hline $\begin{array}{l}\text { Científicos } \\
\text { de } \\
\text { Física }\end{array}$ & 10,5 & 33,0 & 49,5 & 7,0 & 7,5 \\
\hline $\begin{array}{l}\text { Científicos } \\
\text { de } \\
\text { Química }\end{array}$ & 15,0 & 43,0 & 38,0 & 4,0 & 4,5 \\
\hline $\begin{array}{l}\text { Sócio- } \\
\text { psicoló- } \\
\text { gicos }\end{array}$ & 9,5 & 28,5 & 45,5 & 16,5 & 6,5 \\
\hline $\begin{array}{l}\text { Metodológicos } \\
\text { do ensino } \\
\text { da Física }\end{array}$ & 7,0 & 24,5 & 53,5 & 15,0 & 9,0 \\
\hline $\begin{array}{l}\text { Metdológicos } \\
\text { do ensino } \\
\text { da Química }\end{array}$ & 8,0 & 30,0 & 51,0 & 11,0 & 5,0 \\
\hline $\begin{array}{l}\text { Avaliação } \\
\text { da aprendizagem } \\
\text { dos alunos }\end{array}$ & 7,5 & 20,0 & 46,0 & 26,5 & 3,0 \\
\hline $\begin{array}{l}\text { Organização } \\
\text { funcinamento } \\
\text { da escola }\end{array}$ & 16,0 & 25,0 & 33,5 & 25,5 & 5,5 \\
\hline
\end{tabular}

Uma análise do gráfico $1 *$ revela que os aspectos científicos da Química são aqueles em que, em geral, os professores sentem menos dificuldades, seguidos dos aspectos científicos da Física, sendo os aspectos relacionados com a avaliação da aprendizagem dos alunos e com a organização e funcionamento da escola aqueles que maiores dificuldades apresentam aos professores. Curiosamente enquanto que ao longo do tempo de serviço dos professores há uma tendência para a diminuição das dificuldades encontradas nos aspectos científicos da Física e da Química, socio-psicológicos e metodológicos do ensino da Física e da Química, é nos aspectos de avaliação da aprendizagem dos alunos e de organização e funcionamento da escola que se verifica um aumento dessas dificuldades.

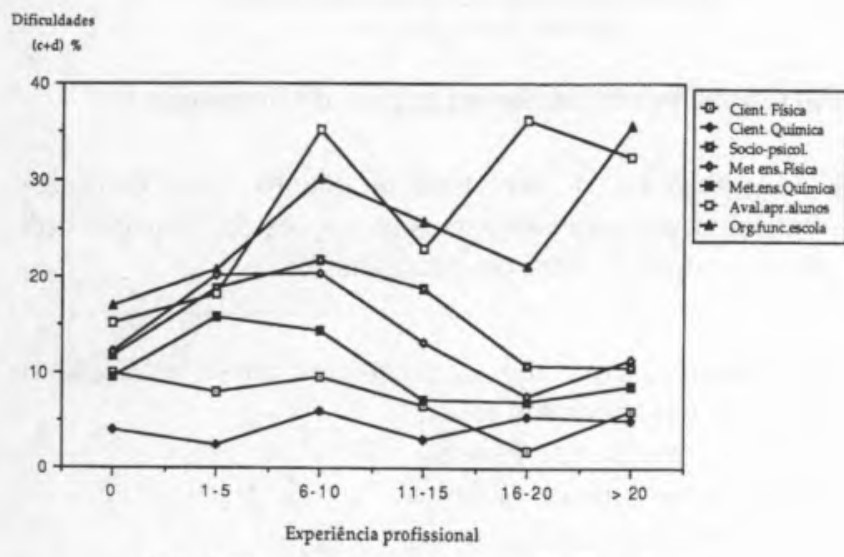

Gráfico 1- Dificuldades encontradas vs experiéncia profissional

\footnotetext{
* Nota: as linhas que unem os pontos dos gráficos apresentados destinam-se somente a permitir uma melhor apreciação da evolução das variáveis consideradas.
}

Tal discrepância é particularmente saliente para os grupos correspondentes aos professores a partir dos 16 anos de serviço. Este facto poderá ser interpretado como sendo o resultado da grande mudança que se deu na sociedade portuguesa há cerca de 15 anos. Na realidade essa mudança teve grandes implicações na escola sobretudo no que diz respeito à relação professor-aluno e aos critérios de avaliação, criando possivelmente aos professores com experiência num determinado contexto, dificuldades de adaptação às novas condicionantes.

Com excepção do grupo entre os 16 e os 20 anos de vida profissional, os aspectos científicos de Física apresentam mais dificuldades aos professores do que os aspectos científicos de Química, embora as variações sejam relativamente pequenas. Nota-se no entanto uma tendência para uma diminuição da diferença entre essas dificuldades à medida que aumenta a experiência profissional dos professores.

Quanto aos aspectos metodológicos são também os relacionados com o ensino da Física que maiores dificuldades apresentam aos professores. Este resultado pode no entanto estar influenciado pela maior dificuldade que os professores sentem em relação aos aspectos científicos de Física. Não se nota no entanto, contrariamente ao que acontece com os aspectos científicos, uma tendência para qualquer diminuição com o aumento de experiência profissional.

\section{Dificuldades e formação académica}

A formação académica aqui referida diz respeito às licenciaturas em Física, ou Química, ramo educacional, e Física e Química. Este último caso envolve as antigas licenciaturas em Física e Química das Faculdades de Ciências e as licenciaturas das Universidades Novas (sendo as primeiras largamente preponderantes na amostra utilizada).

Como se vê no gráfico 2, (dificuldades nos aspectos científicos de Física, nos aspectos científicos de Química e diferença entre essas dificuldades em função da formação académica), o grupo dos licenciados em Física e Química apresenta uma maior homogeneidade nas dificuldades que em geral se apresentam menores do que para os outros licenciados.

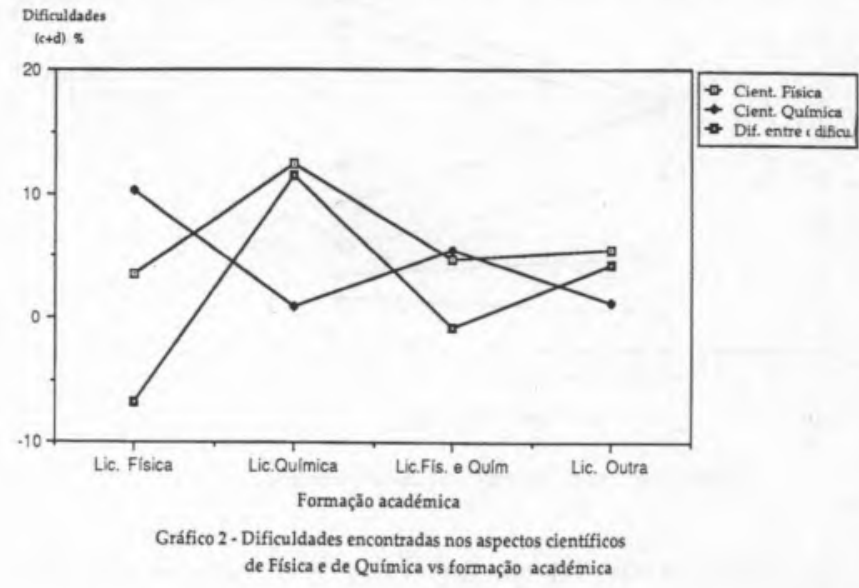

Também no que respeita aos aspectos metodológicos do ensino da Física e do ensino da Química essa homogeneidade é aparente (ver gráf. 3). 


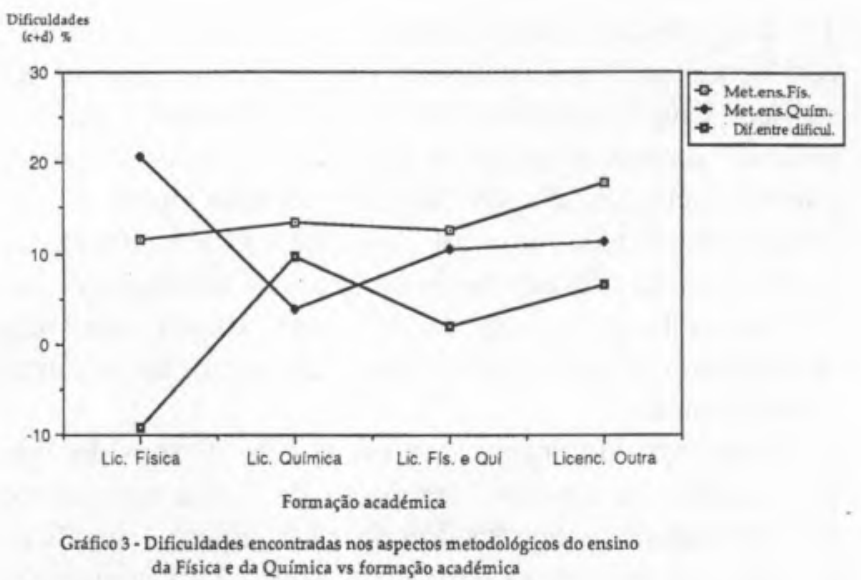

Uma ilação possível desta análise é a que a licenciatura em Física e Química proporciona uma formação mais equilibrada e mais adequada à situação real da leccionação nestes níveis de ensino permitindo aos professores sentirem globalmente menos dificuldades durante a sua prática docente.

\section{Dificuldades e situação profissional}

Nesta análise teve-se em conta apenas os professores provisórios e profissionalizados, não se considerando os estagiários nem os profissionalizados em virtude de, dada a natureza da variável independente em jogo, se considerar que estes dois últimos grupos se encontravam em situação transitória.

A análise do gráfico 4 revela que, em relação aos aspectos de avaliação da aprendizagem dos alunos e organização e funcionamento da escola, os profissionalizados apresentam um aumento de dificuldades relativamente aos provisórios. O mesmo sucede, embora menos acentuado, em relação aos aspectos científicos de Química. Em relação aos outros aspectos nota-se uma diminuição nas dificuldades encontradas sendo esta mais acentuada nos aspectos metodológicos do ensino das duas disciplinas.

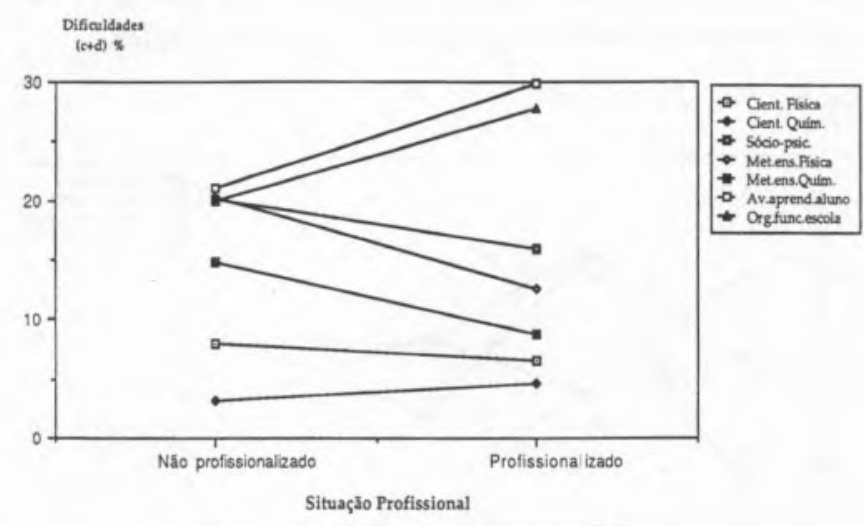

Gráfico 4 - Dificuldades encontradas vs situaşăo profissional

Como tentativa de interpretação das diferenças encontradas no caso da avaliação da aprendizagem dos alunos e organização e funcionamento da escola, procedeu-se à análise das dificuldades referidas pelos professores sobre esses dois aspectos, em função do tipo de profissionalização. A hipótese de trabalho era que, eventualmente, diferentes tipos de formação poderiam ter proporcionado aos professores diferentes capacidades de ultrapassar as dificuldades nessas áreas. Não foi encontrada diferença significativa $(\alpha>0,05)$. Estes resultados impõem uma reflexão profunda e a necessidade de repensar os programas de profissionalização em serviço e a estrutura dos estágios educacionais. Se por um lado estas actividades parecem proporcionar uma maior consciencialização dos professores para as suas dificuldades em determinadas áreas, por outro lado não parecem adequadas para lhes fornecer uma ajuda realmente eficaz, excepto no que diz respeito aos aspectos metodológicos e sociopsicológicos.

\section{Dificuldades e predominância do nível de ensino leccionado pelos professores}

Uma análise do gráfico 5 (dificuldades em função da predominância do nível de ensino leccionado pelos professores) sugere que nos aspectos metodológicos e socio-psicológicos os professores com predominância de ensino do nível secundário sentem menos dificuldades que os com predominância de ensino básico, embora as variações sejam em geral pequenas. $\mathrm{O}$ contrário se verifica em relação aos aspectos científicos quer de Física quer de Química, e aos aspectos relacionados com a avaliação da aprendizagem dos alunos e organização e funcionamento da escola.

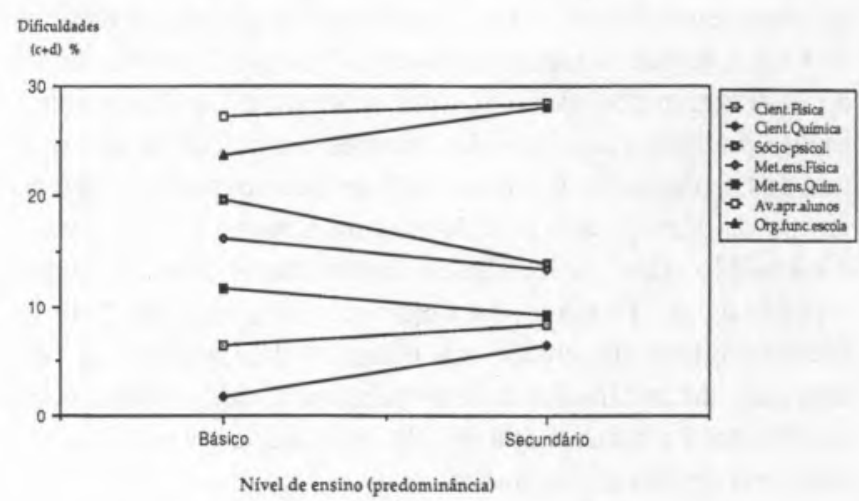

Gráfico 5- Dificuldades encontradas vs predominància do níve! de ensino leccionado pelos professores

\section{Participação em cursos ou acções de formação}

Com o objectivo de investigar há quanto tempo os professores não frequentavam cursos ou acções de formação utilizou-se o seguinte item do questionário:

«Há quanto tempo não frequenta um curso ou acção de formação nas seguintes áreas?

- temas científicos de Física

- temas científicos de Química

- temas socio-psicológicos

- metodologia do ensino da Física

- metodologia do ensino da Química

- avaliação da aprendizagem dos alunos

• organização e administração escolares» 
Para a análise desta questão consideraram-se apenas as respostas dos professores que não tinham participado há mais de 4 anos em qualquer curso ou acção de formação nas áreas indicadas. Não foram considerados os grupos de professores que iniciaram a sua actividade profissional no ano do inquérito.

\section{Participação e experiência profissional}

A configuração dos resultados (gráfico 6) revela que é no início da actividade profissional que os professores mais participam em cursos ou acções de formação em qualquer dos temas apontados. É de realçar que é sobre temas científicos de Física e de Química que em média os professores mais participam, não havendo grandes variações ao longo da experiência profissional após os 5 primeiros anos. No entanto é nos temas em que as dificuldades apontadas pelos professores são maiores, (ver gráfico 1), nomeadamente sociopsicológicos e organização e funcionamento da escola, que em média a participação é menor. Este resultado sugere que será talvez nestas áreas que um sério esforço deverá ser feito a nível de formação contínua, reforçando aliás a conclusão já atrás referida.

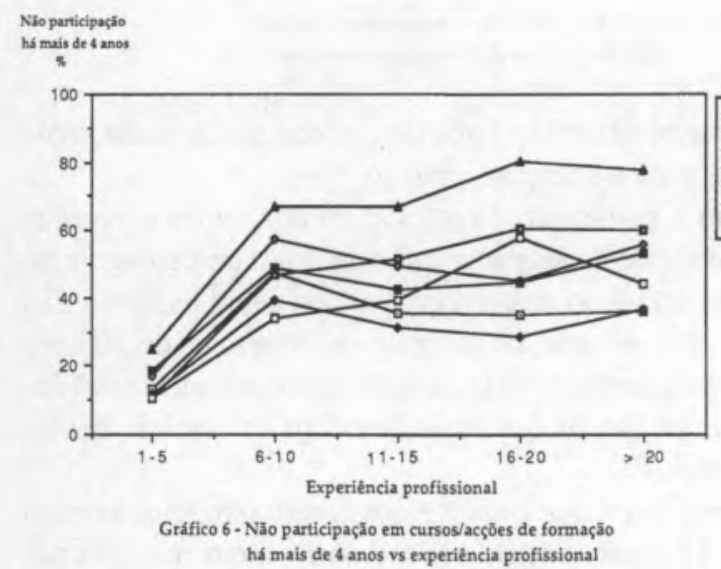

\section{Participação e formação académica}

Os resultados obtidos (gráfico 7), são consistentes com a análise anterior pois revelam que, independentemente da sua diferente formação académica, também é na área de organização e funcionamento da escola que é maior o número de professores que há mais de quatro anos não participa em cursos ou acções de formação.

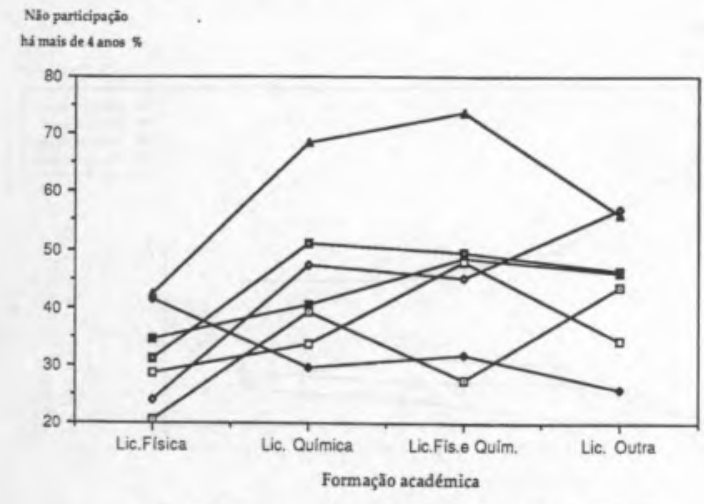

Gráfico 7- Näo participaçăo em cursos de formạão há mais de 4 anos vs formaşão académica
De salientar que de entre os professores inquiridos são os licenciados em Física que apresentam uma participação mais equilibrada e mais recente relativamente a todos os temas. Os resultados sugerem também que os professores com outras licenciaturas participam com mais frequência em cursos ou acções de formação em temas científicos de Química do que de Física, embora, como se viu no gráfico 2, seja em relação aos aspectos científicos de Física que são sentidas, por este grupo, maiores dificuldades.

\section{Participação e situação profissional}

A análise do gráfico (gráfico 8), revela uma tendência geral, nalguns casos bastante acentuada, para um aumento na percentagem de profissionalizados que não participavam há mais de 4 anos em cursos ou acções de formação. Este resultado pode ser interpretado como sendo a consequência do facto dos profissionalizados, embora tendo reconhecimento de sentirem maiores dificuldades em alguns aspectos, (gráfico 4), não sentirem qualquer estímulo exterior que os leve a procurar a participação nesses cursos. Este é um aspecto que merece reflexão em relação à creditação a atribuir a este tipo de actividades, com consequências na progressão na carreira docente dos professores.
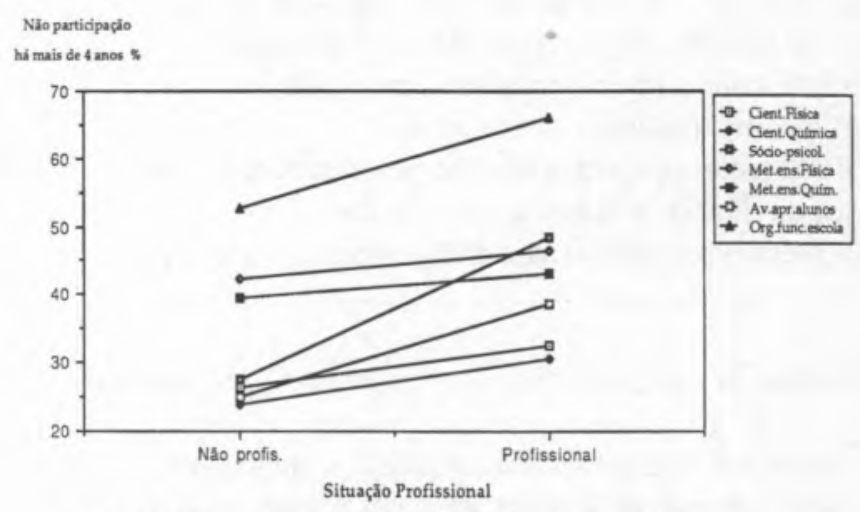

Gráfico 8 - Não participaçăo em cursos/aç̧ōes de formação há mais de 4 anos vs situação profissional

Participação e predominância do nível de ensino leccionado pelos professores

Os resultados relativos a esta questão estão representados no gráfico 9 .
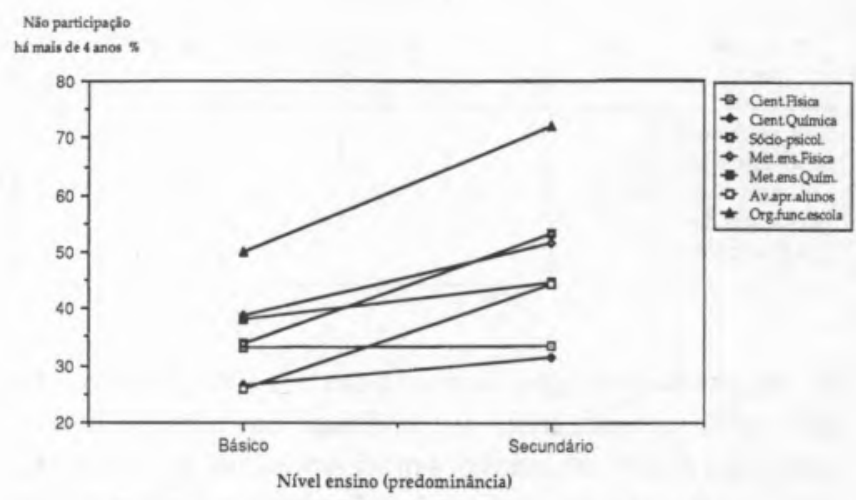

Gráfico 9 - Não participação em cursos/açōes de formação há mais de 4 anos vs predomináncia do nivel de ensino leccionado pelos professores 
Estes resultados revelam que é maior a percentagem de professores com predominância de ensino no nível secundário que há mais de 4 anos não participavam em cursos ou acções de formação nos temas apontados, com excepção dos aspectos científicos de Física. No entanto, como se vê no gráfico 6, nos aspectos científicos de Química, avaliação e organização e funcionamento da escola estes professores sentiam mais dificuldades que os professores com predominância de ensino no ensino básico.

Consistente com as análises já feitas em relação às outras variáveis, é também na área da organização e funcionamento da escola que em ambos os grupos existe uma maior percentagem de não participação em cursos ou acções de formação sobre este tema.

\section{Razões de não participação em cursos ou acções de formação}

Os dados para investigar as razões da não participação há mais de 4 anos em cursos ou acções de formação foram obtidos através das respostas dadas ao seguinte item do questionário:

«No caso de não ter frequentado um curso/acção de formação há mais de 4 anos isso deve-se a (uma ou várias)

- não ter tido conhecimento da sua realização

- teve conhecimento mas não participou por

i) incompatibilidade de horários

ii) os temas propostos não lhe pareceram relevantes

iii) duvidar da eficácia desses cursos

iv) ter outros meios mais eficazes para se actualizar»

\section{Razões de não participaçâo e experiência profissional}

O desconhecimento da existência dos cursos/acções de formação parece ser a razão principal de não participação dos professores, com excepção para o grupo com mais de 20 anos de vida profissional.

QUADRO V

Percentagem de professores que indicaram nāo ter tido conhecimento da existência dos cursos/acções de formação

\begin{tabular}{|c|c|c|c|c|c|c|}
\hline $\begin{array}{c}\text { Esperiência } \\
\text { Porfissional } \\
\text { (anos) }\end{array}$ & 0 & $1-5$ & $6-10$ & $11-15$ & $16-20$ & $>20$ \\
\hline $\begin{array}{c}\text { \% de professores } \\
\text { com desconhe- } \\
\text { cimento da } \\
\text { existência dos } \\
\text { cursos/acçōes }\end{array}$ & 100 & 62,5 & 49,3 & 46,7 & 50,0 & 36,5 \\
\hline
\end{tabular}

Este resultado pode significar uma das três situações: i) ou os cursos não se realizaram, ii) ou foram em número insuficiente para as necessidades dos professores, iii) ou o processo de divulgação da sua realização não chegou à maioria dos professores. É importante que as instituições de formação tenham em atenção este resultado que implica a necessidade duma maior frequência de cursos/acções de formação bem como a sua eficaz divulgação. Este último requisito poderá ser melhor alcançado se, os formadores destas instituições se deslocarem às escolas onde se reunirão os professores das escolas próximas e assim garantir a participação dum maior número de participantes.

No gráfico 10 estão representadas, em função da experiência profissional, as percentagens de professores que tendo tido conhecimento da existência dos cursos/acções de formação, nelas não participaram pelas razões indicadas.

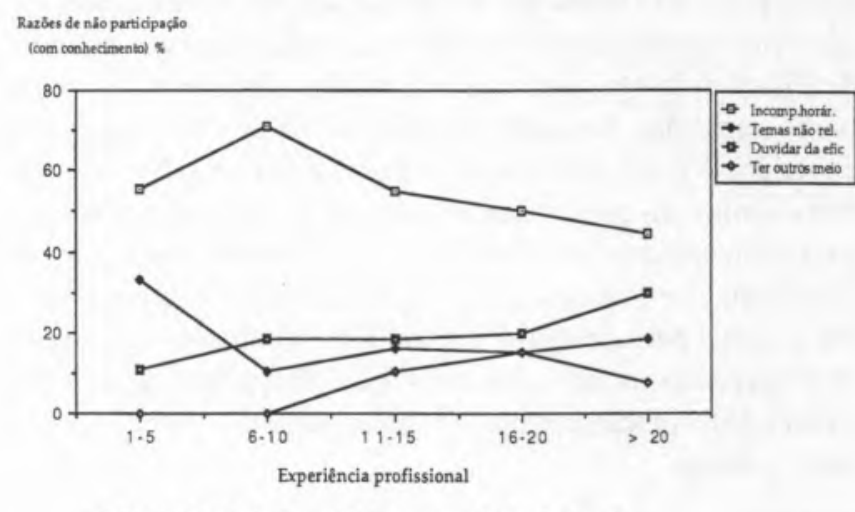

Gráfico 10 - Razōes de não participaçăo em cursos/aç̧ōes de formação (tendo tido conhecimento) vs experiência profissional

A incompatibilidade de horários parece ser a razão mais importante para a não participação.

Em relação à percepção da relevância dos temas propostos nas actividades é de salientar que é maior a percentagem de professores no início da carreira que considera os temas não relevantes. No entanto, os professores com mais de 20 anos de experiência profissional, embora reconhecendo a relevância dos temas, são os que mais duvidam da eficácia desses cursos/acções.

É importante notar que os professores com tempo de serviço inferior a 11 anos sentem não ter outro meio mais eficaz, além dos apontados, para se actualizarem.

\section{Razões de não participação e formação académica}

A análise do gráfico 11 confirma o resultado de que é a incompatibilidade de horários a razão principal apontada pelos professores para a não participação. Os licenciados em Física indicam-na mesmo como a única razão.

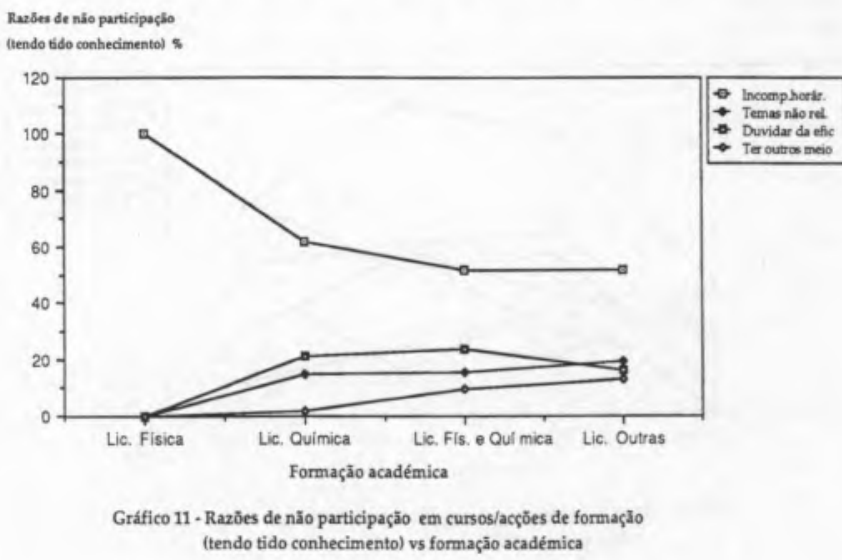


Duvidar da eficácia desses cursos/acções parece ser a razão que, a seguir à incompatibilidade de horários, mais leva os licenciados em Química e Física a não frequentarem esses cursos/acções.

\section{Razões de não participação e situação profissional}

A análise do gráfico 12 (razões apontadas em função da situação profissional) revela que embora sejam os professores profissionalizados os que mais duvidem da eficácia dos cursos, maior é a percentagem destes professores que considera os temas relevantes. este resultado está em concordância com o obtido da análise do gráfico 10 , na medida em que 93\% dos professores profissionalizados têm predominância do nível do ensino secundário [3].

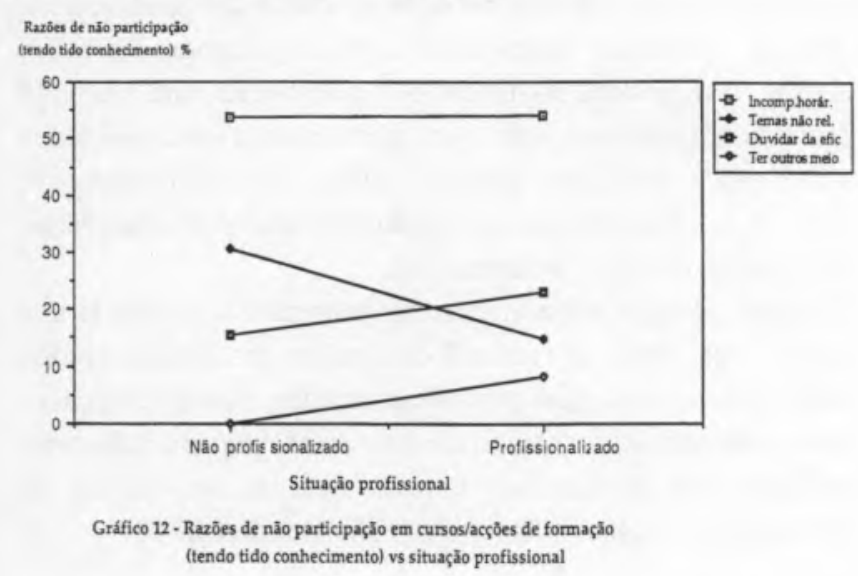

Poderá inferir-se daqui que a profissionalização provoca nos professores uma maior consciencialização, alertando-os para a necessidade do aprofundamento de diversos temas e portanto para a relevância de cursos/acções nessas áreas. No entanto pode acontecer que as suas próprias experiências relativas à participação nessas actividades tenham sido desencorajantes e ineficazes para ajudar os professores a ultrapassar as dificuldades por eles sentidas.

É também de salientar que, enquanto que os professores não profissionalizados indicam não ter outros meios para a sua actualização, o mesmo não acontece com os profissionalizados. Este resultado pode ser interpretado atendendo a que a profissionalização, proporcionando um estado de maior consciencialização e reflexão, leva os professores a sentirem a necessidade de procurar outros meios alternativos que thes permitam ultrapassar as dificuldades encontradas.

Razões de não participação e predominância do nível de ensino leccionado

Embora a análise do gráfico 13 (razões de não participação em função da predominância do nível de ensino leccionado) continue a revelar que é a incompatibilidade de horários a razão de maior peso para a não participação em cursos/acções, ela mostra que essa razão não é tão importante para os professores com predominância de ensino no secundário como para os que têm predominância de ensino no básico.

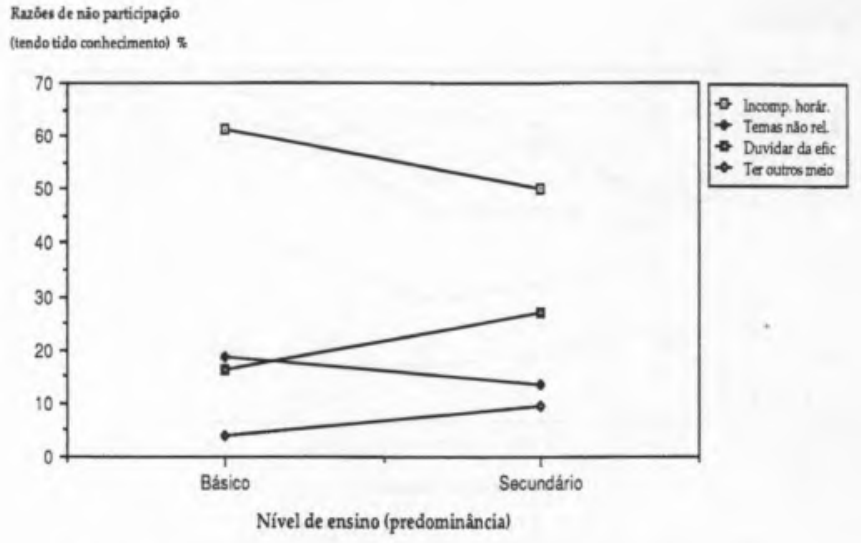

Gráfico 13 - Razōes de não participação em cursos/aç̧ôes de formação

(tendo tido conhecimento) vs predominància do nível de ensino leccionado

O facto de ser maior a percentagem de professores com predominância de ensino no secundário que têm a percepção da ineficácia dos cursos/acções de formação, pode querer dizer que estes cursos, embora sobre temas relevantes, não estejam adequadamente orientados para as suas necessidades.

É interessante notar a consistência de comportamento desta variação com a variação analisada anteriormente (comparar os gráficos 12 e 13).

\section{Importância relativa das actividades de formação}

Para investigar esta questão utilizou-se o seguinte item do questionário:

«Qual a importância que atribui a cada uma das seguintes actividades para o/a ajudar a ultrapassar dificuldades no exercício das suas funções docente:

- cursos específicos a ter lugar nas universidades

- conferências/colóquios/mesas redondas/seminários/ateliers (workshops)

- discussão informal com colegas da sua ou de outras escolas

- visitas de estudo

- consulta de publicações científicas e/ou pedagógicas»

\section{Importância das actividades \\ e experiência profissional}

Os resultados apresentados no gráfico 14, (importância das actividades em função da experiência profissional), revelam que são as visitas de estudo as actividades que os professores consideram menos importantes para a resolução das suas dificuldades, seguida das conferências/colóquios/etc. Este resultado é independente dos anos de serviço. Nota-se, no entanto, uma tendência para a atribuição duma maior importância relativa das outras actividades à medida que aumenta a experiência profissional. 


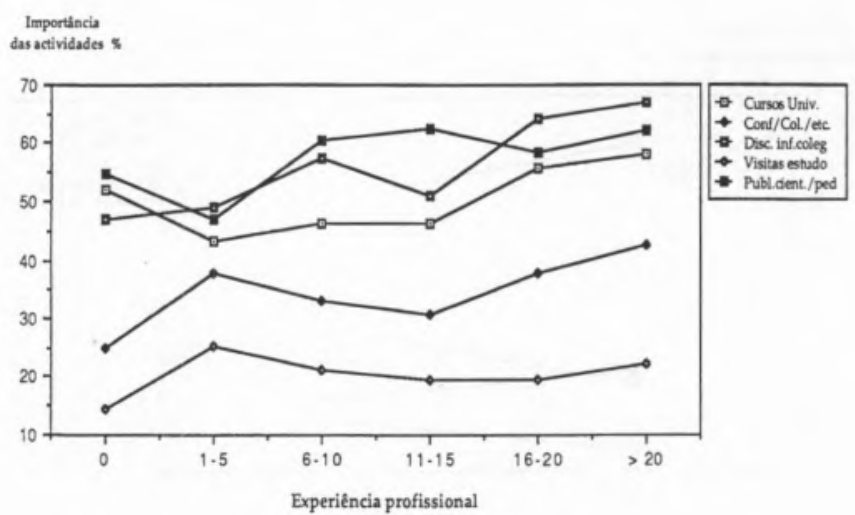

Gráfico 14 - Importância das actividades de formação vs experiència profissional

A consulta de publicações científicas e/ou pedagógicas e as discussões informais com os colegas parecem ser, de entre as actividades apresentadas as que os professores, em geral, consideram mais importantes para a resolução dos seus problemas. É interessante verificar que para os professores com mais de 16 anos de experiência profissional são aquelas últimas que consideram mais importantes. Aos cursos a ter lugar nas universidades é atribuída pelos professores uma relevância mediana.

\section{Importância das actividades e formação académica}

No gráfico 15 estão representados os resultados relativos a esta questão. Eles indicam que, com ligeiras alterações, a preferência dos professores mantém o perfil encontrado anteriormente.

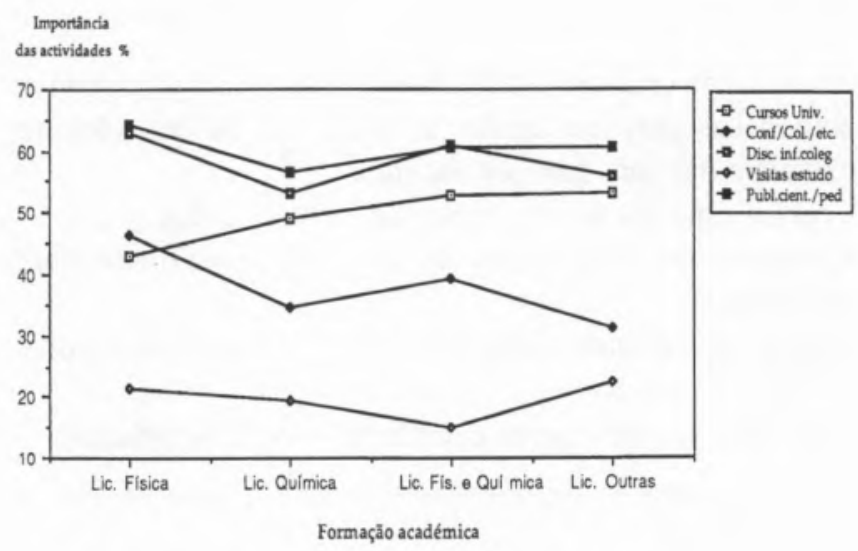

Gráfico 15 - Importáncia das actividades de formação vs formação académica

Importância das actividades e situação profissional

Embora mantendo a mesma importância relativa para as diferentes actividades os resultados representados no gráfico 16, (importância das actividades em função da situação profissional), revelam que os professores profissionalizados atribuem ainda menos importância às visitas de estudo que os não profissionalizados mas mais às conferências/colóquios/ /etc.

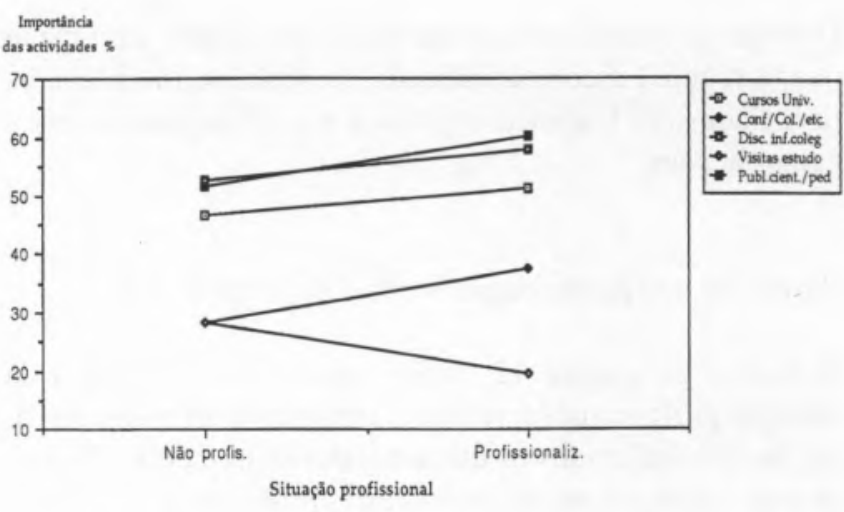

Gráfico 16 - Importáncia das actividades de formaçăo vs situação profissional

As opiniões dos professores relativamente às visitas de estudo poderão estar influenciadas pelo facto de as identificarem com as visitas de estudo, por eles programadas, para os alunos. Isso poderá significar que não tiveram na sua vida profissional oportunidades para participarem em actividades deste tipo, o que sugere que, na planificação de programas de F. C. se deve ter em conta a exploração das potencialidades deste meio tão rico de formação.

Também se nota um aumento na importância atribuída aos outros três tipos de actividades pelos profissionalizados relativamente aos não profissionalizados o que reforça as conclusões tiradas nas análises anteriores quanto à consciencialização da necessidade e relevância de actividades de formação em consequência da profissionalização.

\section{Importância das actividades \\ e predominância do nivel de ensino leccionado pelos professores}

O gráfico 17, (importância das actividades em função da predominância do nível de ensino leccionado), indica que os professores com predominância do nível de ensino no secundário diferenciam mais os cinco tipos de actividades dando maior preferência às consultas de revistas científicas ou pedagógicas do que os professores com predominância de ensino no básico.

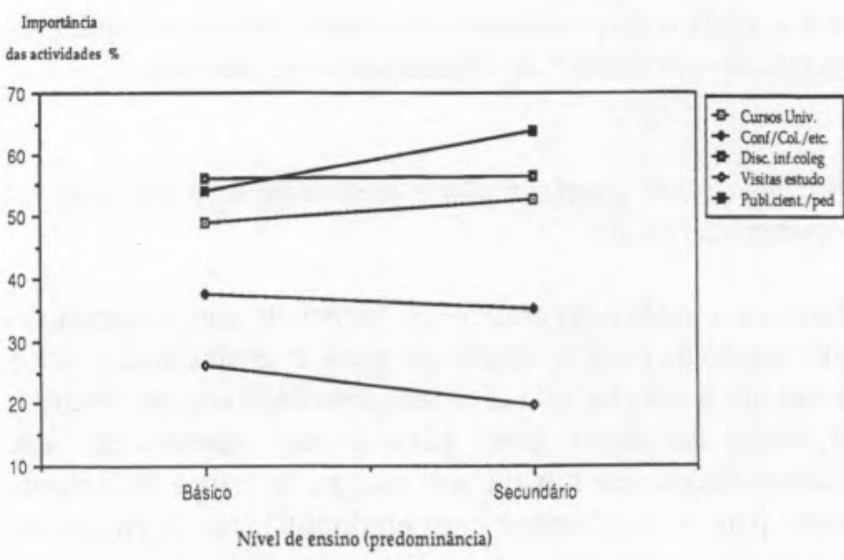

Gráfico 17 - Importáncia das actividades vs predominancia do nível de ensino leccionado 


\section{CONCLUSŌES}

A implementação da Reforma do Sistema de Ensino em Portugal passa por uma adequada formação inicial e contínua de professores. De acordo com esta lógica e tendo em vista delinear estratégias de intervenção tendo por base a investigação educacional, identificaram-se neste estudo alguns aspectos que devem ser contemplados na formação contínua de professores de Física e Química. Tais aspectos podem, no essencial, ser categorizados em quatro grandes grupos que de algum modo se intersectam:

- prioridade das áreas de formação

- condições de realização das acções de formação

- mudança de atitude dos professores

- creditação institucional em termos de progressão na carreira docente

\section{Prioridade das áreas de formação}

Os resultados deste estudo identificam as áreas relacionadas com a avaliação da aprendizagem dos alunos e com a organização e funcionamento da escola como as que merecem uma atenção especial em programas de F. C. a implementar. Isto impõe a urgência duma investigação mais exaustiva no sentido de diagnosticar as necessidades específicas dos professores nestas duas áreas de modo a poder programar acções eficazes.

Quanto aos actuais estágios e programas de profissionalização em serviço, os resultados parecem também indicar que, se por um lado eles proporcionam aos professores uma maior consciencialização das suas próprias dificuldades, sobretudo em relação aos aspectos científicos, por outro lado a natureza destas actividades parece não ser a mais adequada para os ajudar a superá-las. No entanto, relativamente aos aspectos metodológicos elas parecem contribuir para uma ajuda eficaz.

Especificamente relacionado com os aspectos científicos e metodológicos o estudo aponta para os licenciados em Física e Química como os menos carenciados de acções de F. C.. Este resultado sugere a necessidade de definir critérios para a constituição dos grupos que irão participar nas diferentes aç̧ões a implementar. Implica também uma profunda reflexão sobre a natureza e estrutura de cursos de formação de professores, não só em Física e Química mas em outras licenciaturas com características bidisciplinares idênticas, relativamente às quais se poderão vir a obter resultados paralelos.

\section{Condiçôes de realizaçāo das acçōes de formaçāo}

A dificuldade de acesso a cursos/aç̧ões de formação, quer por desconhecimento da sua existência quer por incompatibilidade de horários, apontadas pelos professores como as principais razões de não participação, impõe uma atenção especial não só no que diz respeito a uma eficaz divulgação destas actividades, como na escolha do local para a sua realização. Se tais acções forem centradas nas escolas isso poderá contribuir para uma maior participação dos professores interessados.
Estes resultados implicam também uma necessidade de institucionalizar processos de dispensa do trabalho docente através de, por exemplo, licenças sabáticas por determinados períodos e com uma determinada periodicidade.

\section{Mudança de atitudes dos professores}

Um aspecto salientado pelos resultados desta investigação diz respeito à atitude de cepticismo demonstrada pelos professores com maior experiência profissional em relação à eficácia da F. C..

Para provocar uma mudança de tal atitude será importante que a programação das acções a desenvolver seja baseada em resultados de investigação educacional que permitam: (i) identificar as reais necessidades dos professores; (ii) estabelecer prioridades relativamente ao tipo de formação inicial dos professores a participar nessas acções; (iii) definir os objectivos, conteúdos e estratégias de acordo com a população a abranger; (iv) explorar toda a potencialidade dos vários tipos de actividades de formação existentes, (por exemplo o caso das viagens de estudo para formação de docentes), e (v) fazer uma avaliação dos processos de formação.

Pensamos que é também importante, para esta desejada mudança de atitude, a existência de estímulos exteriores ao próprio indivíduo, um dos quais é focado a seguir.

\section{Creditação institucional em termos de progressão na carreira docente}

Um resultado de certo modo preocupante diz respeito à fraca participação em acções de formação dos professores após os primeiros anos de actividade profissional. De acordo com este estudo são os professores profissionalizados os que menos participam nestas aç̧ões. A não creditação das acções de F. C. para efeitos de progressão na carreira docente poderá estar na origem desta situação. Este facto deverá ser motivo de reflexão e actuação dos órgãos competentes de modo a contribuir para uma maior adesão de todos os professores à participação em programas de F. C..

Em nossa opinião, só ressalvando, reflectida e cuidadosamente, os aspectos atrás considerados, será possível dar real consecução ao ponto 1 do Artigo $35^{\circ}$ da Lei de Bases do Sistema Educativo:

A todos os educadores, professores e outros profissionais de educação é reconhecido o direito à formação contínua.

\section{Referências}

[1] Ministério da Educação, GSERE (1097), Ante-Projecto de formação contínua dos docentes do ensino não superior, - Bases Gerais -

[2] Hofstein, A., (1983), «Research». Preservice and Inservice Training in Science Teachers. P., Tamir, A. Sciences Services, Philadelphia, Rehovot.

[3] Cachapuz, A. F., Malaquias, I. M., Martins, I. P., Marilia, F. Thomaz, Vasconcelos, N., «Resultados de um inquérito nacional aos professores de Física e Química - $3^{\circ}$ Ciclo do Ensino Básico e Ensino Secundário». Monografia, Universidade de Aveiro (em impressão). 
instrumentos de laboratófio e eientíficos lda

LISBOA PORTO PONTA DELGADA

$A A-I C P-F T-I R-U V-V I S-G C-H P L C$

TERMO ANÁLISE - BIOQUIMICA - UV - NIR

PERKIN ELMETR

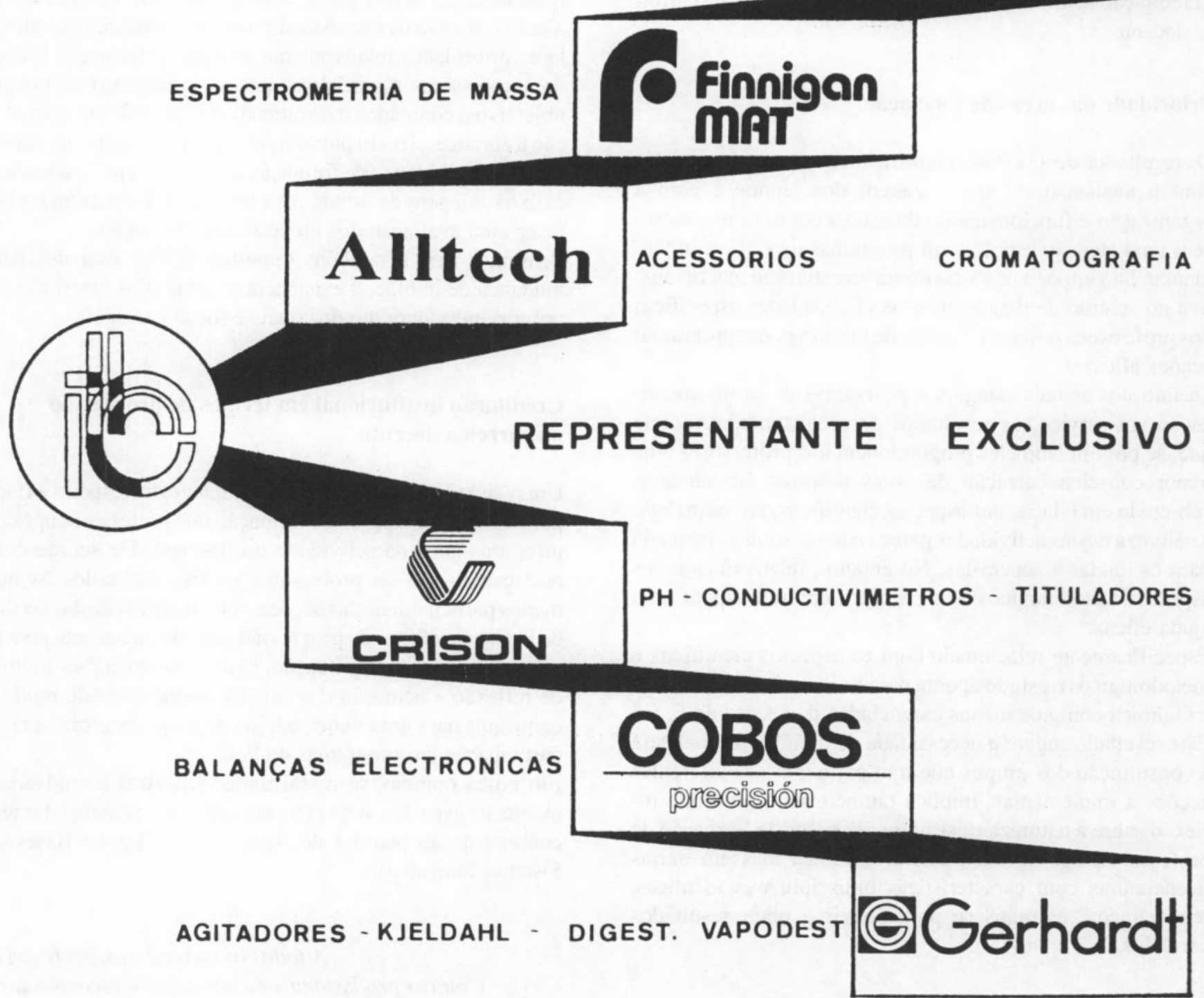

ATAGO - ASTELL ELMA FISHER SCIENTIFIC J.U.M.

HANSATECH - INGOLD T. D. F. ORBECO/HELLIGE 